\title{
Sediment Transport and Its Impacts on Lake Kivu, Gihira Water Treatment Plant and Various Hydropower Plants along Sebeya River in Rwanda
}

\section{Félicien Majoro ${ }^{1 *}$, Umaru Garba Wali ${ }^{1}$, Omar Munyaneza ${ }^{1}$, François-Xavier Naramabuye ${ }^{2}$, Eric Derrick Bugenimana ${ }^{3}$, Concilie Mukamwambali ${ }^{4}$}

\author{
${ }^{1}$ Department of Civil, Environmental and Geomatics Engineering, College of Science and Technology, University of Rwanda, \\ Kigali, Rwanda \\ ${ }^{2}$ College of Agriculture Science and Veterinary Medicine, University of Rwanda, Kigali, Rwanda \\ ${ }^{3}$ Faculty of Agriculture and Rural Development, University of Kibungo, Kibungo, Rwanda \\ ${ }^{4}$ Department of Mathematics, Science and Physical Education, College of Education, University of Rwanda, Rwamagana, Rwanda \\ Email: *majoro.felicien@yahoo.fr
}

\begin{abstract}
How to cite this paper: Majoro, F., Wali, U.G., Munyaneza, O., Naramabuye, F.-X., Bugenimana, E.D. and Mukamwambali, C. (2020) Sediment Transport and Its Impacts on Lake Kivu, Gihira Water Treatment Plant and Various Hydropower Plants along Sebeya River in Rwanda. Journal of Water Resource and Protection, 12, 934-950. https://doi.org/10.4236/jwarp.2020.1211055
\end{abstract}

Received: September 29, 2020

Accepted: November 23, 2020

Published: November 26, 2020

Copyright $\odot 2020$ by author(s) and Scientific Research Publishing Inc. This work is licensed under the Creative Commons Attribution International License (CC BY 4.0).

http://creativecommons.org/licenses/by/4.0/ (c) $\underset{\mathrm{By}}{\mathrm{B}}$ Open Access

\begin{abstract}
Complex processes of sediment transport in a river impact on overall aquatic system and result in the productivity decrease of socio-economic development projects taking the river as a source of water. The present study was designed to estimate Sebeya river sediment load and assess its impacts on Lake Kivu, Gihira water treatment plant and various hydropower plants constructed in Sebeya catchment located in Western Province of Rwanda. Water samples were hand-collected from five different sampling points along Sebeya river during rainy and dry seasons. Laboratory analysis for turbidity, total suspended solids, sieve analysis for bed load materials and NPK content of water samples were conducted. The results revealed that the average turbidity was found to be high during rainy season compared to dry season. The same trend was found in total suspended solids concentrations. At all 5 sampling sites and during rainy season compared to dry season, the average mass flowrates of bed load materials were 7.84 and $2.96 \mathrm{~kg} / \mathrm{hr}$ respectively. Sieve analysis results showed that all bed load sediments were mainly composed of high proportions of fine sand of more than $70 \%$ which adversely causes damages on hydropower turbines and the effect of high soil erosion rates on Gihira water treatment plant was traduced by high turbidity of raw water and excessive costs of reagents. At Sebeya outlet, nutrients load and high turbidity reduce significantly the aesthetic quality of Lake Kivu, having a harmful impact on recreation and tourism, aquatic life and affect the livelihoods of people living
\end{abstract}


in the vicinity. Researchers recommend two options of reducing the amount of sediment load in Sebeya river: either to prevent soil erosion or to trap eroded sediment at the upstream of the hydropower and the water treatment plants. Assessing the sediment load fluctuations in Sebeya river is useful for water managers and planners to adjust operations accordingly at water treatment and hydropower plants.

\section{Keywords}

Sebeya River, Impacts of Sediment Load, Lake Kivu, Rwanda

\section{Introduction}

Surface water plays a significant role in the development of a country and individual citizens as sources of food, water, transport, hydropower and recreation [1]. Thus, high concentration of sediments in water retrogrades the economy of a country and the polluted water affect the livelihoods of people living in the vicinity and can kill aquatic life.

Globally, soil erosion increases the amount of sediment transported in rivers at a rate of 2.3 billion tons per year [2]. In most watersheds of Rwanda, sediment transported in rivers varies proportionally to the rate of erosion, river runoff and the land slope [3] while soil nutrients (organic materials, nitrogen, phosphorus and potash) were lost due to soil erosion at rates of 945,200, 41,210, 200 and 3055 tons/year respectively [4]. For the case of Sebeya river in the Western part of Rwanda, the transported sediments lead to scour on bridge, increase pollutants in water bodies and reduce the performance of hydro power plants [5].

Recently, water quality was monitored by Rwanda Water and Forest Authority (RWFA) at the outlet of Sebeya river flowing into Lake Kivu. The measurements revealed excessive turbidity and Total Suspended Solids (TSS) of 1102 NTU and $4414.5 \mathrm{mg} / \mathrm{L}$ respectively [6].

Explicitly, there was no specific study which has been conducted to monitor sediment transport in Sebeya River and its impacts. The objectives of the present study were to estimate Sebeya river sediment loading rates and propose mitigation measures to minimize its impacts on Lake Kivu, Gihira water treatment and various hydropower plants along Sebeya river.

\section{Data and Methods}

\subsection{Study Area}

Situated in Africa, Lake Kivu is one of the Great Lakes of the East African Rift valleys. With a total surface area of $2700 \mathrm{~km}^{2}$, an altitude of 1460 metres above sea level, and a maximum depth about 480 metres, the Lake Kivu is shared by Rwanda and the Democratic Republic of Congo (DRC). The Lake Kivu is fed by 127 rivers whose source is the Congo Nile Crest, from the North-West to the 
South-West of Rwanda including Sebeya river [1].

This study is entirely focused on Sebeya level 2 catchment which is a part of the larger level 1 Lake Kivu catchment and located in the Western Province of Rwanda as presented in Figure 1. The main river flowing in this catchment is Sebeya, which originates in the mountains of Rutsiro District. The catchment is shared by four administrative units namely Rubavu, Nyabihu, Rutsiro and Ngororero (Figure 1).

On a total area of $363.1 \mathrm{~km}^{2}$, the average population density of Sebeya catchment is estimated to $644 \mathrm{hab} / \mathrm{km}^{2}$ while the average population density of Rwanda is about 415 habitants per $\mathrm{km}^{2}$ [6] [7]. Sebeya catchment is located in the high elevation region of the country with altitude varying between $1462 \mathrm{~m}$ to $2979 \mathrm{~m}$ a.b.s.l. (meters above sea level). The soil in this catchment favors agriculture due to its high infiltration rates and its high minerals content except for the case of clay soils on flat topography encountered in the catchment. Sebeya catchment is also characterised by steep slopes (varying from $0 \%$ to $90 \%$ ) and abundant rainfall varying between $1200 \mathrm{~mm}$ to $1700 \mathrm{~mm}$ per year [6] revealing that a great part of this catchment falls in medium risk to very high risk of erosion according to the classification of Ministry of environment [8].

\subsection{Data Collection}

\subsubsection{Sebeya Discharge Measurement and Sampling Sites}

Water samples were hand-collected from five different sampling points along Sebeya River (NYB, KY, GH, GSH and SO) during rainy and dry seasons. Sebeya river discharges were measured using the area velocity method, commonly known as current meter method. Current meter uses a propeller component to

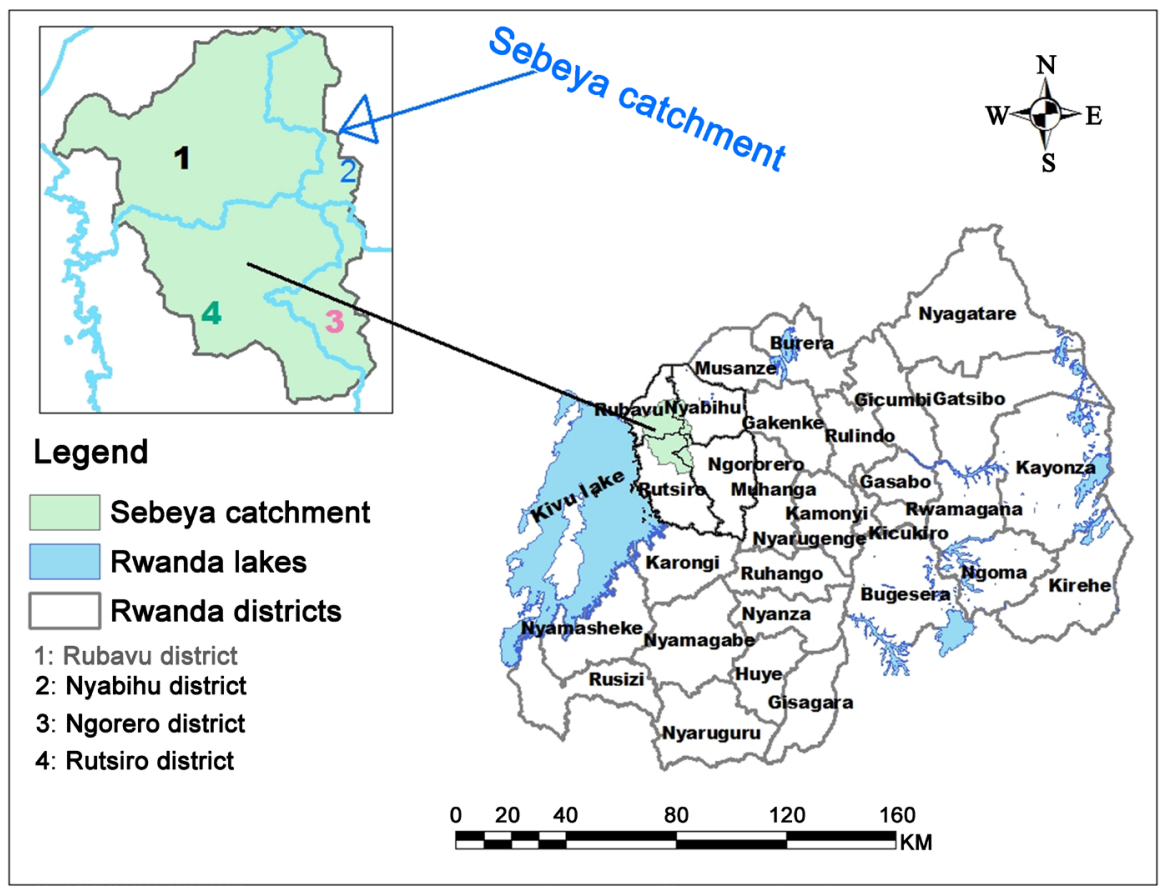

Figure 1. Location of Sebeya catchment on Rwanda map. 
measure the local velocity of flow (v) and water depth was measured using a tape measure. As described by Le Coz et al. [9], the mean-section method was used to calculate the total discharge $(\mathrm{Q})$ by integration of the velocity $(\mathrm{v})$ over the river cross section area (A).

Due to the fact that main socio-economic development projects (Gihira WTP and 3 hydropower plants namely Keya, Gihira and Gisenyi HPPs) are concentrated downstream within $12 \mathrm{~km}$ from Lake Kivu, water and bed load samples were collected at the 5 five selected sites along Sebeya river for sampling purpose and presented in Figure 2. The samples were taken to chemistry laboratory of University of Rwanda, College of Science and Technology where different parameters

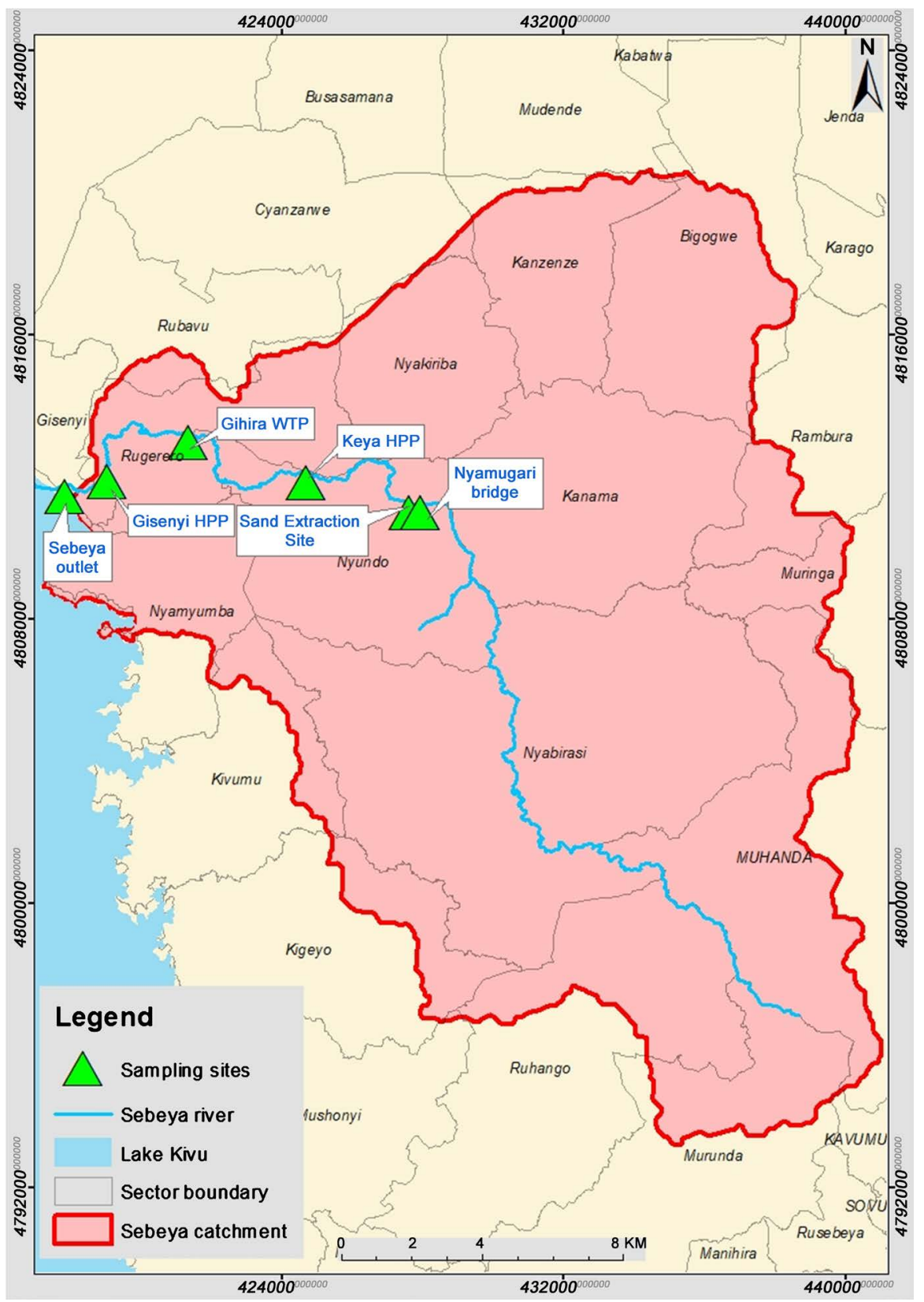

Figure 2. Sampling points. 
were analyzed including total suspended solids, turbidity and NPK nutrients content.

\subsubsection{Sampling and Laboratory Tests for Suspended Solids and Turbidity} In order to compare the results of this study, sampling period was extended from rainy season to dry season (Table 2). The width of the river at Nyamugari bridge is $8 \mathrm{~m}$ and the depth of water was about $0.60 \mathrm{~m}$ at that date and time. At Figure 3, a field technician taking water samples in Sebeya river for TSS and turbidity analysis. Successively at $(2 \mathrm{~m}, 4 \mathrm{~m}$ and $6 \mathrm{~m})$ along Sebeya river width from the left river bank, a sampling bottle of $500 \mathrm{ml}$ was inserted at $15 \mathrm{~cm}$ below the water surface for prevention of disturbance due to floating debris [10]. From a well-mixed collection of the 3 water samples, $500 \mathrm{~mL}$ water sample was taken for laboratory analysis.

\subsubsection{Suspended Sediment Determination Procedures}

From each water sample of $500 \mathrm{ml}$ taken from the respective sampling site, a small quantity of $100 \mathrm{ml}$ was placed in an aluminium sheet plate which was then heated on a hot plate for about 30 minutes in order to vaporize water. The humid residues left on the aluminium sheet plate was then dried in the oven at $105^{\circ} \mathrm{C}$ for 24 hours and after that time the dried TSS was weighed and the concentration of TSS determined in $\mathrm{mg} / \mathrm{l}$.

\subsubsection{Turbidity Measurement}

Turbidity meter is a complex and delicate instrument which needs to be calibrated before its use. In this study, a $50 \mathrm{ml}$ water sample was poured in a turbidity grass which was then placed in the turbidity meter to allow readings of the turbidity values in NTU.

\subsubsection{Sebeya Bed Load Sampling}

Samples were hand-collected in the catchment at five selected sampling points.

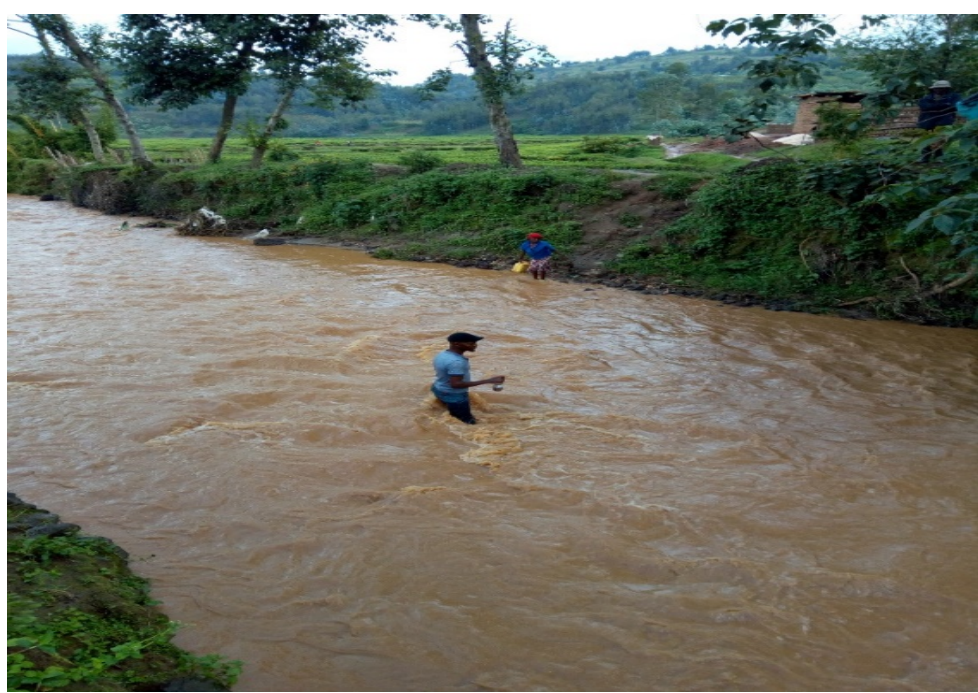

Figure 3. Sebeya river water sampling. 
The sampler used for this study (Figure 4) was designed referring to the description given by [11]. The characteristics of the designed sampler are as follows: opening front size of $0.3 \mathrm{~m} * 0.2 \mathrm{~m}$ (large enough to allow sediments to enter), total length of $0.9 \mathrm{~m}$ and the mesh size of $3.9 \mathrm{~mm}$ (for capturing different sizes of sediments greater than $3.9 \mathrm{~mm}$ ). For bed load sampling, 3 samplers were immersed at the bottom of the river at 3 equidistant points along the river cross-section (at $2 \mathrm{~m}$, at $4 \mathrm{~m}$ and at $6 \mathrm{~m}$ from the river bank). Before starting the sampling process, the mass of each empty sampler was recorded and samplers placed in contact with the river bed against the flow, allowing the sediment transported as bed load to accumulate or be trapped inside the sampler for $1 \mathrm{hr}$ (Long duration for the collection of infrequently moving large particle sizes near the threshold of motion). After one hour, the samplers were raised up to the surface and the weight of the content of each sampler was recorded. The bed load from the 3 samplers were well mixed and $1 \mathrm{~kg}$ taken from this mixture for further analysis in the laboratory.

\subsubsection{Sieve Analysis for Bed Load Aggregates}

Laboratory procedures were performed by sieve analysis as per IS: 2386 (Part I) - 1963 to determine the particle size distribution of the coarse and fine aggregates. Different sieves with different sizes $(20 \mathrm{~mm}, 10 \mathrm{~mm}, 8 \mathrm{~mm}, 6 \mathrm{~mm}, 4.75$ $\mathrm{mm}, 3.35 \mathrm{~mm}, 2.36 \mathrm{~mm}, 1.18 \mathrm{~mm}, 600 \mu \mathrm{m}, 300 \mu \mathrm{m}, 150 \mu \mathrm{m}$ and $75 \mu \mathrm{m}$ ). The bed load sediment composition was determined using MIT (Massachusetts Institute Technology) grain size classification standard.

\section{Results and Discussions}

\subsection{Actual Situation of Soil Erosion in Sebeya Catchment}

Soil erosion within Sebeya catchment was categorized into 6 classes such as 0 - 5 very low, 5 - 10 low, 10 - 25 moderate, 25 - 50 high, 50 - 100 very high and greater than 100 extremely high in tons/ha/year where around 8000 ha are under high risk, around 6000 ha under very high risk while around 4000 ha are under extremely high risk of soil erosion [8]. In Sebeya catchment, the high risk of soil erosion results from improper management of land, heavy rainfall and human activities that disturb the soil.

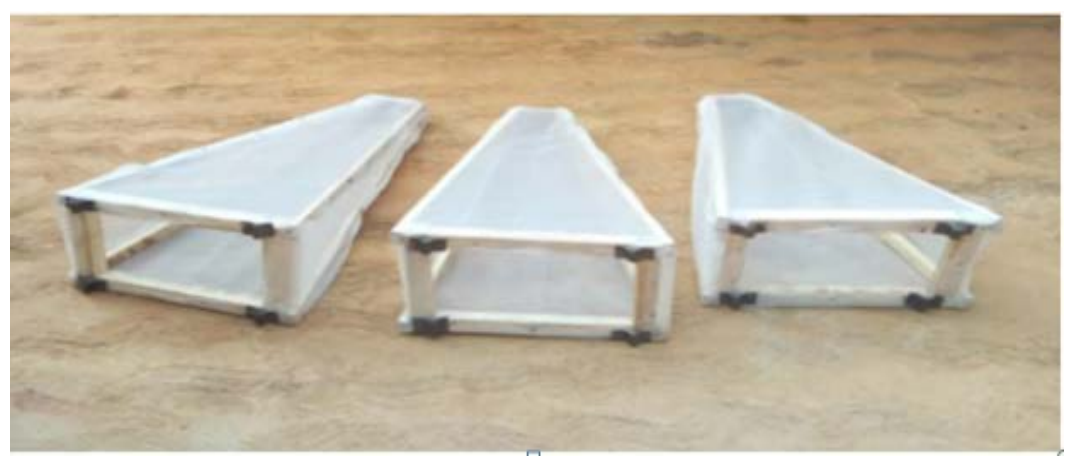

Figure 4. Bed load sampler. 


\subsection{Monitoring Discharge, Bed Load Rates and Water Quality of Sebeya River}

\subsubsection{Sebeya Discharge Fluctuation}

Sebeya river discharge measurement was performed at Nyamugari bridge situated at Kanama Sector in order to determine the value of the surface outflow generated by Sebeya catchment and its temporal variability. By knowing the discharge Q $\left(\mathrm{m}^{3} / \mathrm{s}\right)$ and TSS $(\mathrm{mg} / \mathrm{l})$ we can deduce the mass of TSS $(\mathrm{kg})$ passing through the river per day. The measurement of discharge has also high impact on sediment transport that leads to hydropower and water treatment plants damages [12]. For low water level at about $60 \mathrm{~cm}$, a current meter was used to measure the stream velocity at each selected interval and the corresponding discharges were calculated as presented in Table 1. Considering all sampling dates as shown in the Table 1, the average Sebeya river discharge was $2.245 \mathrm{~m}^{3} / \mathrm{s}$. During heavy rainfall event, the discharge was found to be high in Sebeya river and reduced significantly after rainfall event.

Water resources occupy $8 \%$ of the total area of Rwanda but due to lack of data, it is difficult to estimate at which extent the climate change has impacted on water resources [13]. The following statements stand for the sediments loading rates and water quality in Sebeya river (Table 2).

\subsubsection{Sediments Loading Rates in Sebeya River}

In broadest context, soil erosion is responsible for increasing river sediment

Table 1. Monitoring of Sebeya river discharge.

\begin{tabular}{cc}
\hline Date & Discharge $\left(\mathrm{m}^{3} / \mathrm{s}\right)$ \\
\hline 27-Sep 18 & 2.005 \\
07-Oct-18 & 1.853 \\
03-Nov-18 & 2.946 \\
17-Nov-18 & 2.178 \\
Mean & 2.245 \\
\hline
\end{tabular}

Table 2. Sediments loading rates and water quality in Sebeya river.

\begin{tabular}{|c|c|c|c|c|c|c|c|c|c|c|c|c|c|c|c|c|c|c|}
\hline \multirow{3}{*}{$\begin{array}{c}\text { Sampling } \\
\text { points }\end{array}$} & \multirow{2}{*}{\multicolumn{2}{|c|}{$\begin{array}{c}\text { Bed load } \\
(\mathrm{kg} / \mathrm{hr})\end{array}$}} & \multirow{2}{*}{\multicolumn{2}{|c|}{ TSS (mg/l) }} & \multirow{2}{*}{\multicolumn{2}{|c|}{$\begin{array}{l}\text { Turbidity } \\
\text { (NTU) }\end{array}$}} & \multicolumn{6}{|c|}{ NPK of Bed load } & \multicolumn{6}{|c|}{ NPK of water samples } \\
\hline & & & & & & & \multicolumn{2}{|c|}{$\mathrm{N} \%$} & \multicolumn{2}{|c|}{$\mathrm{P} \%$} & \multicolumn{2}{|c|}{$\mathrm{K} \%$} & \multicolumn{2}{|c|}{ N\% } & \multicolumn{2}{|c|}{$\mathrm{P} \%$} & \multicolumn{2}{|c|}{$\mathrm{K} \%$} \\
\hline & RS & DS & RS & DS & RS & DS & RS & DS & RS & DS & RS & DS & RS & DS & RS & DS & RS & DS \\
\hline NYB & 10.4 & 5.3 & 2790 & 227 & 880 & 208 & 0.76 & 0.32 & 0.81 & 0.26 & 0.14 & 0.10 & 0.29 & 0.12 & 0.58 & 0.37 & 0.56 & 0.45 \\
\hline KY & 8.0 & 3.3 & 3033 & 220 & 667 & 242 & 0.56 & 0.44 & 0.55 & 0.41 & 0.34 & 0.17 & 0.45 & 0.26 & 0.62 & 0.32 & 0.60 & 0.4 \\
\hline GH & 6.0 & 4.6 & 1904 & 546 & 778 & 598 & 0.59 & 0.14 & 0.68 & 0.26 & 0.16 & 0.08 & 0.44 & 0.35 & 0.69 & 0.33 & 0.58 & 0.25 \\
\hline GSH & 11.1 & 0.7 & 2160 & 263 & 872 & 801 & 1.80 & 0.34 & 1.59 & 0.26 & 0.39 & 0.18 & 0.24 & 0.19 & 0.72 & 0.37 & 0.60 & 0.36 \\
\hline SO & 3.7 & 0.0 & 2092 & 423 & 693 & 440 & 0.15 & 0.00 & 0.28 & 0.00 & 0.15 & 0.00 & 0.29 & 0.18 & 0.38 & 0.18 & 0.60 & 0.28 \\
\hline Mean & 7.84 & 2.78 & 2395 & 336 & 778 & 458 & 0.77 & 0.25 & 0.78 & 0.24 & 0.24 & 0.11 & 0.34 & 0.22 & 0.60 & 0.31 & 0.59 & 0.35 \\
\hline
\end{tabular}

Sampling dates: [RS: Rainy season (26/04/2019, 3/5/2019 and 18/5/2019); DS: Dry season (26/07/2019, 8/2/2019 and 8/8/2019)]. 
loading rates with two major types of pollution related to the physical and chemical composition of the sediment [14] [15].

\subsubsection{Quantification of Total Suspended Solids (TSS) in Sebeya River}

An important parameter for the analysis of water quality is the concentration of Total Suspended Solids (TSS) because these types of solids are good indicators of physical and aesthetic degradation of surface water quality [16] [17].

\subsubsection{Turbidity Fluctuation in Sebeya River}

Due to soil erosion, the top soil and soil nutrients are carried into rivers, lakes and water reservoirs resulting in high turbidity. In general, water is more turbid during rainy season as compared to dry season (Table 2). The turbidity is an important parameter which helps to judge the water quality and it gives the idea on purification work to be carried out [18].

\subsubsection{Nutrients Loading Rates in Sebeya River}

Nutrients lost from agricultural fields due to soil erosion, particularly nitrogen and phosphorus, become common pollutants in waterbodies and are largely responsible for what is known as "eutrophication". Eutrophication is a process in which excess fertility in a waterbody leads to excessive plant growth, low dissolved oxygen, bad odors and the production of toxic substances by blue-green algae which may cause human diseases or kill fishes and other aquatic animals [19] [20] [21].

\subsection{Impacts of Sebeya River Sediments on Keya, Gihira and Gisenyi Hydropower Plants}

\subsubsection{Sebeya River Bed Load}

The variation in mass flow rates of bed load was studied during the two seasons. Table 2 and Figure 5 show that higher values of bed load sediments were observed during rainy season and decreased significantly during dry season. Sedimentation affects the stability of dams, reduces the reservoirs storage and the carrying capacity of rivers which consequently reduces the hydropower production and flood attenuation capabilities. Large scour may be developed at bridge

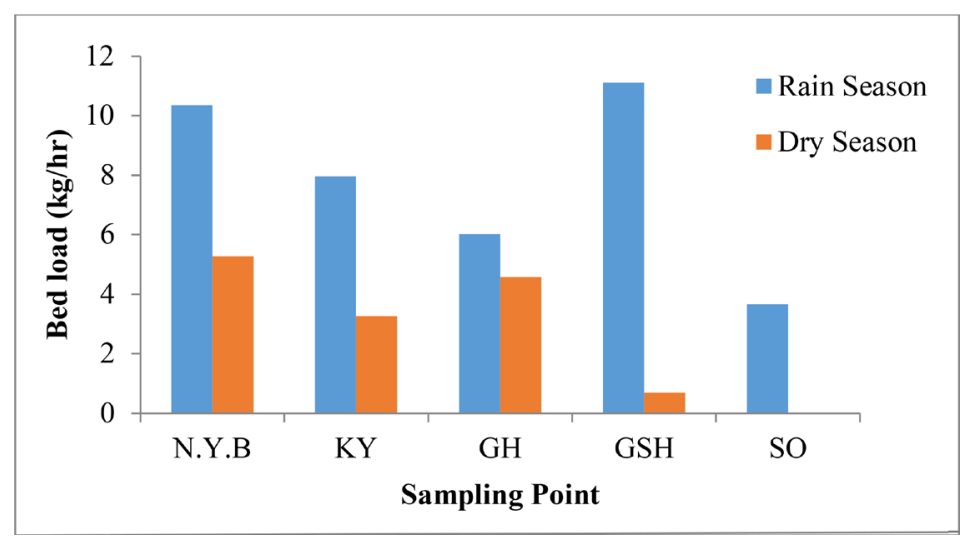

Figure 5. Variation of bed load mass flow rates. 
piers and abutments threatening their structural integrity [22].

\subsubsection{Composition of Bed Load Aggregates}

In Table 3, sieve analysis results showed that almost all bed load samples were mainly composed of high proportions of fine during dry season at more $70 \%$. Other remaining portions such as silt, clay, coarse sand, gravel, and medium sand showed low percentages. Sand materials cause abrasion on the hydraulic turbines and consequently reduce the performance of the hydropower plant in producing electricity [5] [23].

After comparing sediment concentration at the inlet and outlet of the sediment basin, it was found that the basin removed only $22 \%$ of sediment from diverted water toward the turbine. This means that $78 \%$ of sediment escapes the basin to cause erosion on the turbine components resulting in reduction of the plant capacity from 2.2 MW to $900 \mathrm{KW}$ [5]. It is therefore important to enforce erosion control measures within Sebeya catchment in order to mitigate the impacts of sedimentation by reducing the volume of sediment that is brought to the hydropower intakes by Sebeya river. Alternatively, a sediment basin can be built for trapping suspended sediments before they reach the turbine components. Developments in achieving a more sustainable sediment management strategy are of high interest for HPPs, owners, environmental agencies and local government [24].

\subsection{Impacts of Soil Erosion on Gihira Water Treatment Plant}

Storm water is a main leading cause of water pollution. Along this study, water quality was monitored at 5 different points along Sebeya river during rainy and dry season and the results are presented in the following sections.

\subsubsection{Suspended Solids}

From Table 2, the average Total Suspended Solids (TSS) for both seasons are plotted in the same graph as shown in Figure 6. The higher values of suspended solids were observed in the rainy season at all sampling points comparatively to

Table 3. Sieve analysis results of bed load sediment during rainy and dry season

\begin{tabular}{|c|c|c|c|c|c|c|c|c|c|c|}
\hline \multirow{3}{*}{$\begin{array}{l}\text { Sampling } \\
\text { point }\end{array}$} & \multicolumn{10}{|c|}{ Bed load composition (\%) } \\
\hline & \multicolumn{2}{|c|}{$\begin{array}{l}\text { (Silt + Clay) } \\
(<0.06 \mathrm{~mm})\end{array}$} & \multicolumn{2}{|c|}{$\begin{array}{c}\text { Fine Sand } \\
(0.2-0.06 \mathrm{~mm})\end{array}$} & \multicolumn{2}{|c|}{$\begin{array}{l}\text { Medium Sand } \\
(<0.6-0.2 \mathrm{~mm})\end{array}$} & \multicolumn{2}{|c|}{$\begin{array}{l}\text { Coarse Sand } \\
(2-0.6 \mathrm{~mm})\end{array}$} & \multicolumn{2}{|c|}{$\begin{array}{c}\text { Gravel } \\
(60-2 \mathrm{~mm})\end{array}$} \\
\hline & RS & DS & RS & DS & RS & DS & RS & DS & RS & DS \\
\hline NYB & 5.41 & 17.57 & 69.68 & 74.68 & 22.21 & 6.40 & 1.20 & 0.98 & 1.50 & 0.36 \\
\hline KY & 6.37 & 8.10 & 57.20 & 70.30 & 33.33 & 18.8 & 2.20 & 2.10 & 0.90 & 0.70 \\
\hline GH & 6.00 & 7.68 & 55.55 & 71.76 & 33.84 & 18.8 & 3.43 & 1.30 & 1.18 & 0.50 \\
\hline GSH & 5.49 & 14.40 & 54.61 & 70.20 & 31.30 & 13.5 & 4.90 & 1.54 & 3.70 & 0.40 \\
\hline so & 4.06 & 0.00 & 67.504 & 0.00 & 21.60 & 0.00 & 2.48 & 0.00 & 4.44 & 0.00 \\
\hline
\end{tabular}

Sampling dates: [RS: Rainy season (26/04/2019, 3/5/2019 and 18/5/2019); DS: Dry season (26/07/2019, $8 / 2 / 2019$ and $8 / 8 / 2019)]$. 
dry season. Spatially, there is a small increase of TSS from Nyamugari bridge to its downstream Keya hydropower due to a frequent illegal mining of sand and unimproved agriculture practices between these 2 river sections. However, from the inlet of Gisenyi HPP to Sebeya outlet, the river bed is flat which allows water to flow at a small velocity and then facilitates suspended particles to settle down.

\subsubsection{Turbidity}

Turbidity is proportional to the availability of clay, silty and sand from organic and inorganic matters [25]. Table 2 and Figure 7 illustrate the variation of the measured turbidity in Sebeya River along rainy and dry seasons. During rainy season, both suspended sediments and turbidity increase due to soil erosion and low conservation measures in Sebeya catchment. All turbidity values in two seasons are above permissible limit for drinking water at every sampling point. This is one of the issues faced by Gihira water treatment plant in terms of excessive costs of reagents for treating high turbid raw water (Table 4).

\subsection{Estimation of Nutrients (NPK) in Sebeya River}

Nitrogen, Phosphorus and Potassium (NPK) are the typical vital plant nutrients found in the eroded soil materials. In this study, samples of water and bed load were collected to determine NPK content present in Sebeya river. All nutrients parameters were found to be high during rainy season and decreased during dry season (Table 2 and Figure 8). It is obvious that NPK nutrients were present in

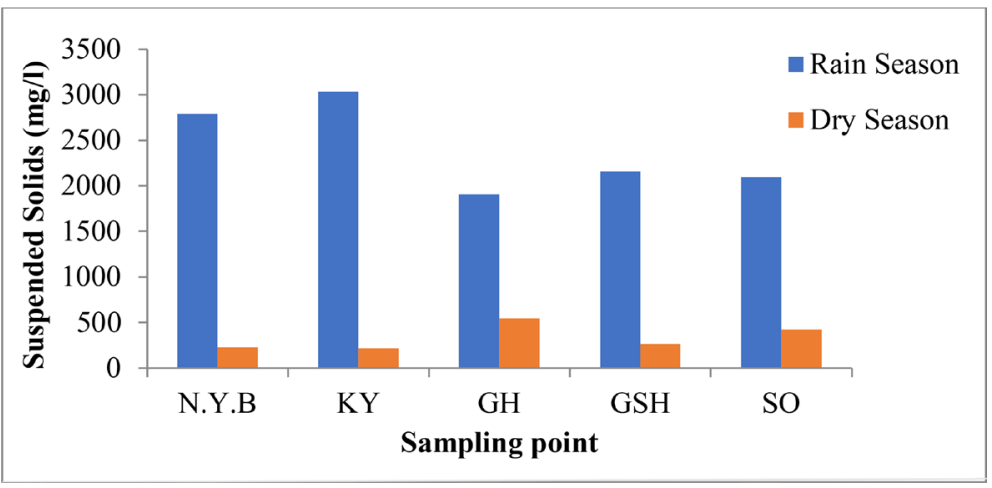

Figure 6. Variation of suspended solids.

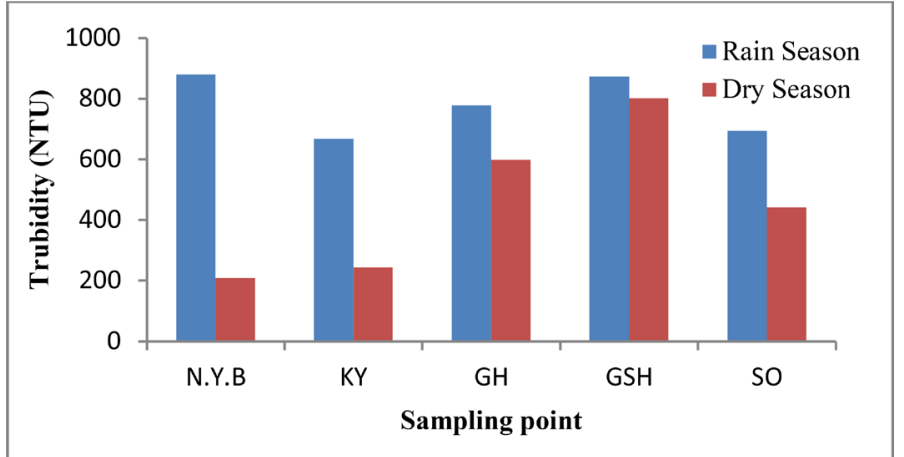

Figure 7. Variation of turbidity. 


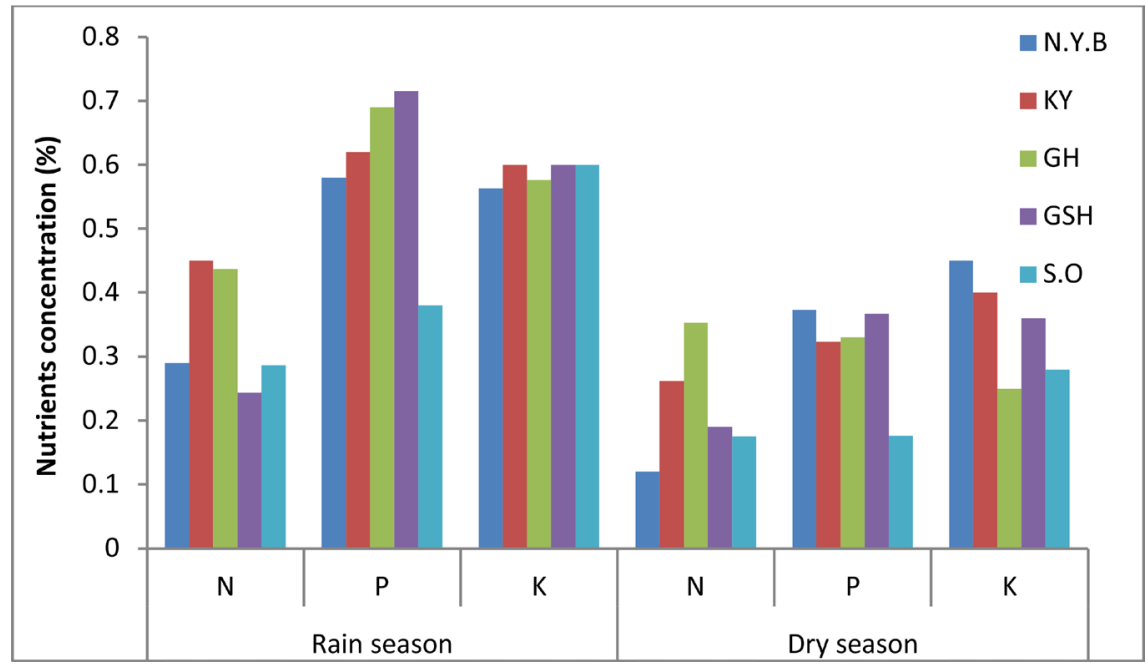

Figure 8. NPK variation in Sebeya river water samples.

water samples and variably changing among the five sampling points. The increase of nutrients in Sebeya river is directly linked with the presence of sediments. Nutrients are mainly associated with agricultural effluent [19].

It is very necessary to treat water and make water sources suitable for human consumption through the removal and killing of pathogenic organisms and removal of the taste, smell, and other undesirable chemical and physical constituents. Various treatment processes which are used to take out impurities from raw water may be arranged in a treatment sequence as: flocculation, sedimentation, filtration, and disinfection of water.

\subsection{Effects of Sediment Load on the Performance of Gihira WTP}

The effects of sediments load on the performance of a water treatment plant are: high turbidity, high cost of coagulants to be used in water treatment, low quantity of water to be supplied, damage of valves and taps, filters blockages, fills of tanks and pipes with mud and silt and it can also be causing the delay in water treatment process.

In this study, the effect of soil erosion on Gihira WTP was assessed while considering raw water quality in terms of turbidity and südfloc consumed seasonally. Received from Rwanda Water \& Sanitation Corporation (WASAC), the Table 4 quantifies various parameters of raw water and treated water at Gihira WTP from 2011 to 2017. Explicitly, the impact of soil erosion on Gihira WTP can be illustrated by the following statements:

- The turbidity due to high river sediment loads is more in rainy season than in dry season.

- The removal efficiency of turbidity is very high (about 99\%). All turbidity values of the treated water comply with World Health Organization (WHO) and Rwanda drinking water standards of 5 - 25 NTU [18].

- If the turbidity of raw water increases, the südfloc consumption will also increase for the same quantity of raw water to be treated. 
Table 4. Monthly volume of water with its turbidity and südfloc consumed [26].

\begin{tabular}{|c|c|c|c|c|c|c|c|}
\hline \multirow[b]{2}{*}{ Year } & \multirow{2}{*}{$\begin{array}{c}\text { RW } \\
\text { or TW }\end{array}$} & \multicolumn{3}{|c|}{ Rainy season (March-May) } & \multicolumn{3}{|c|}{ Dry season (June-September) } \\
\hline & & $\begin{array}{c}\text { Discharge } \\
\left(\mathrm{m}^{3}\right)\end{array}$ & $\begin{array}{c}\text { Turbidity } \\
\text { (NTU) }\end{array}$ & $\begin{array}{l}\text { südfloc } \\
(\mathrm{kg})\end{array}$ & $\begin{array}{c}\text { Discharge } \\
\left(\mathrm{m}^{3}\right)\end{array}$ & $\begin{array}{c}\text { Turbidity } \\
\text { (NTU) }\end{array}$ & südfloc $(\mathrm{kg})$ \\
\hline \multirow[b]{2}{*}{2011} & RW & $175,718.3$ & 875.33 & \multirow[b]{2}{*}{3696.67} & $189,876.3$ & 204.67 & \multirow[b]{2}{*}{2681.67} \\
\hline & TW & $149,959.0$ & 2.07 & & $180,024.7$ & 1.03 & \\
\hline \multirow[b]{2}{*}{2012} & RW & $144,704.7$ & 599.00 & \multirow[b]{2}{*}{3003.00} & $186,975.7$ & 159.67 & \multirow[b]{2}{*}{2943.33} \\
\hline & TW & $129,699.7$ & 1.20 & & $177,898.0$ & 0.70 & \\
\hline \multirow{2}{*}{2013} & RW & $257,365.3$ & 656.57 & \multirow{2}{*}{3915.00} & $277,667.3$ & 181.33 & \multirow{2}{*}{2950.00} \\
\hline & TW & $248,676.3$ & 1.68 & & $275,565.0$ & 1.96 & \\
\hline \multirow{2}{*}{2014} & RW & $269,065.0$ & 108.27 & \multirow{2}{*}{5316.67} & $274,755.0$ & 891.63 & \multirow[b]{2}{*}{6441.67} \\
\hline & TW & $267,926.7$ & 2.30 & & $271,919.3$ & 1.87 & \\
\hline \multirow{2}{*}{2015} & RW & $295,026.0$ & 451.94 & \multirow{2}{*}{5621.67} & $298,780.0$ & 577.88 & \multirow{2}{*}{4000.00} \\
\hline & TW & $268,205.7$ & 1.50 & & $271,618.3$ & 1.62 & \\
\hline \multirow[b]{2}{*}{2016} & RW & $259,426.0$ & 1378.13 & \multirow[b]{2}{*}{2030.00} & $288,549.2$ & 1106.53 & \multirow{2}{*}{1470.00} \\
\hline & TW & $247,072.7$ & 2.21 & & $278,805.0$ & 400.32 & \\
\hline \multirow{2}{*}{2017} & RW & $266,478.2$ & 1609.67 & \multirow{2}{*}{5183.33} & $291,115.3$ & 1164.77 & \multirow{2}{*}{5060.00} \\
\hline & TW & $253,788.7$ & 1.65 & & $280,746.0$ & 1.62 & \\
\hline
\end{tabular}

RW: raw water, TW: treated water.

\subsection{Impacts of Soil Erosion on Lake Kivu}

\subsubsection{Estimation of Daily Sediment Load Rejected into Lake Kivu by Sebeya River}

Sebeya river water depths are automatically recorded by the hydrometric station installed at Nyundo Sector by Rwanda Water Forest Authority. Based on the available data, the channeling capacity of Sebeya river was estimated at $100 \mathrm{~m}^{3} / \mathrm{s}$ [27].

In this study, Figure 5 says that $4 \mathrm{~kg} / \mathrm{hr}$ of sediment bed load are rejected by Sebeya river into Lake Kivu which seems to be negligible compared to the storage capacity of Lake Kivu of $\mathrm{V}=500 \mathrm{~km}^{3}$. However, in flood condition, more sand sediments are seasonally generated and if no preventive measures are taken, the useful storage of Lake Kivu at Gisenyi beach location can be reduced significantly and swimming uses can be negatively affected. High sediment load into the Lake Kivu can also make water less recreational and destroy aquatic habitats (Table 5).

\subsubsection{Estimation of Daily Nutrients Rejected into Lake Kivu by Sebeya River}

Table 2 and Figure 8 describe the variation on NPK in water samples taken from Sebeya river during the 2 seasons of sampling while the Table 2 and Figure 9 indicate the variation of NPK detected from the bed load samples. No bed load sediments were found in the samplers at Sebeya outfall during dry season.

At Sebeya outlet, nutrients loadings into Lake Kivu are mainly linked to heavy 
Table 5. Sediment concentrations and risk to fish [28].

\begin{tabular}{ccc}
\hline SN & Sediment increase $(\mathrm{mg} / \mathbf{l})$ & Risk to fish and their habitat \\
\hline 1 & 0 & No risk \\
2 & $<25$ & Very low risk \\
3 & $25-100$ & Low risk \\
4 & $100-200$ & Moderate risk \\
5 & $200-400$ & High risk \\
6 & $>400$ & Unacceptable risk \\
\hline
\end{tabular}

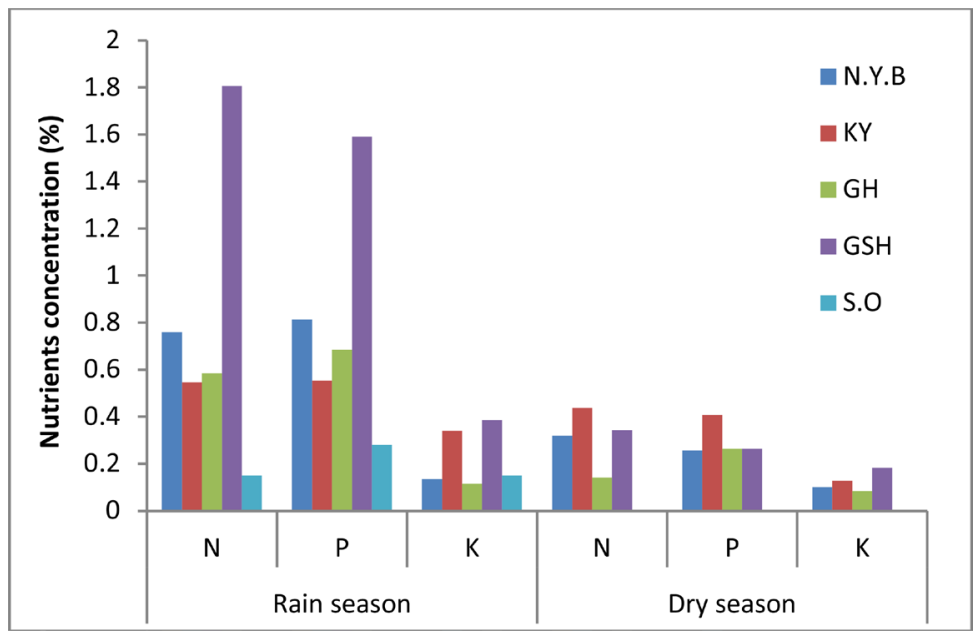

Figure 9. NPK variation in Sebeya river bed load samples.

rainfall which is influenced by the rapid growth of population, deforestation and soil erosion along the Sebeya catchment. At Sebeya outfall, the nutrients load could be prevented.

\subsection{Aesthetic Value of Lake Kivu}

The aesthetic value of lakes has been acknowledged by many researchers [29] who developed the Aesthetic Quality Index (AQI) while considering the following three parameters: taste, odor, turbidity and color.

High turbidity can significantly reduce the aesthetic quality of lakes and streams, having a harmful impact on recreation and tourism. It can harm fish and other aquatic life by reducing aquatic food supplies, degrading spawning beds of lakes and rivers and affecting the gill function of fishes [30].

Obviously (Figure 6 and Figure 7), turbidity and TSS values observed at all 5 sampling points were very high and can be associated by unstable mining and poor agricultural practices favoring erosion that results in high loads of Sebeya river sedimentation.

\subsection{Environmental Mitigation Measures for Adverse Impacts of Sebeya River Sediment Load}

Any mitigation measure reflecting the erosion control within the catchment would 
mitigate the adverse impacts of Sebeya river sediment load by reducing the volume of sediment that is brought to the intakes of 3 hydropower plants, inlet of Gihira WTP or other structures like bridges across the river. There are only two options of reducing the amount of sediment that enters in the reservoirs: to prevent soil erosion or to trap the eroded sediment before it reaches the reservoir [31]. In order to minimize Sebeya river sediment loading rates, the present study strongly recommends the improvement of the existing soil erosion and sediment control measures for high effective performance. As indicated by different research findings, this study also propose to increase the implementation of soil erosion control measures including terraces [4], mulching [32], contour bunds [33], forestation and conservation tillage [34], various slopes stabilization measures, cover crops and vegetation [35], various riverbanks stabilization measures like riverbank stone revetment, grassed waterways [36] and specific sediment control measures such as buffer zones, sediment fences, sediment basin and check dams [37] [38] [39]. These measures have to be adopted basing on the specific area criteria in the Sebeya catchment like land slope, soil depth and other essential characteristics.

\section{Conclusions and Recommendations}

The present study was designed to estimate Sebeya river sediment load and assess its impacts on Lake Kivu, Gihira water treatment plant and various hydropower plants constructed in Sebeya catchment.

This research revealed that the total suspended solids, turbidity, bed load materials and NPK nutrients were found to be high during rainy season compared to dry season. Fine sand proportion was found dominant in the composition of the Sebeya river bed load materials which adversely causes damages on hydropower turbines and the effect of high soil erosion rates on Gihira water treatment plant was traduced by high turbidity of raw water and excessive costs of reagents. At Sebeya outlet, nutrients load and high turbidity reduce significantly the aesthetic quality of Lake Kivu, having a harmful impact on recreation and tourism, aquatic life and affect the livelihoods of people living in the vicinity.

Researchers recommend two options of reducing the amount of sediment load in Sebeya River: either to prevent soil erosion or to trap eroded sediment at the upstream of the hydropower and the water treatment plants.

\section{Acknowledgements}

The authors are grateful to the University of Rwanda (UR) for its support and wish to acknowledge the support of UR-Sweden Program in sponsoring this research and we cannot fail to commend and appreciate the work of various authors used for the present study.

\section{Conflicts of Interest}

The authors declare no conflicts of interest regarding the publication of this paper. 


\section{References}

[1] Muvundja, A.F., Pasche, N., Bugenyi, W.B.F., Isumbisho, M., Müller, B., Namugize, J.P., Rinta, P., Schmid, M., Stierli, R. and Wüest, A. (2009) Balancing Nutrient Inputs to Lake Kivu. Journal of Great Lakes Research, 35, 406-418. https://doi.org/10.1016/j.jglr.2009.06.002

[2] Syvitski, J.P., Smarty, J.V., Kettner, J.A. and Pamela, G. (2005) Impact of Humans on the Flux of Terrestrial Sediment to the Global Coastal Ocean. Science, 308, 376 380. https://doi.org/10.1126/science.1109454

[3] Karamage, F., Hang, C., Ndayisaba, F., Shao, H., Kayiranga, A., Fang, X., Nahayo, E., Nyesheja, M.E. and Tian, G. (2016) Extent of Cropland and Related Soil Erosion Risk in Rwanda. Sustainability, 8, 609. https://doi.org/10.3390/su8070609

[4] Mupenzi, J.P., Li, L., Jiwen, G., Habumugisha, J.D., Habiyaremye, G., Ngamije, J. and Baragahoranye, I. (2012) Radical Terraces in Rwanda. East African Journal of Science and Technology, 1, 53-58.

[5] Munyaneza, O., Majoro, F., Mutake, S. and Hagenimana, E. (2015) Performance Evaluation of Sediment Basins: Case Study of Keya Hydropower Plant in Rwanda. Journal of Water Resource and Protection, 7, 1387-1398. https://doi.org/10.4236/jwarp.2015.716112

[6] IWRM (2018) Sebeya Catchment Plan 2018-2024. Report, Ministry of Natural Resources, Kigali.

[7] NISR (2014) Rwanda Demographic and Health Survey 2014-15. Report, National Institute of Statistics of Rwanda, Kigali.

[8] MoE (2018) Mapping of Erosion in Rwanda and Guidelines for Erosion Control. Report, Ministry of Environment, Kigali.

[9] Le Coz, J., Camenen, B., Peyrard, X. and Dramais, G. (2014) Uncertainty in OpenChannel Discharges Measured with the Velocity-Area Method. Flow Measurement and Instrumentation, 26, 18-29. https://doi.org/10.1016/j.flowmeasinst.2012.05.001

[10] Musselman, R. (2012) Sampling Procedure for Lake or Stream Surface Water Chemistry. U.S. Department of Agriculture, Washington DC.

https://doi.org/10.2737/RMRS-RN-49

[11] Kristin, B. and Steven, R.A. (2002) Sampler Size and Sampling Time affect Bed Load Transport Rates and Particle Sizes Measured with Bed Load Traps in Gravel-Bed Streams. Proceedings of Oslo-Norway Workshop on Erosion and Sediment Transport Measurement in Rivers. Technological and Methodological Advance, Oslo, June 2002, 126-133.

[12] Yüce, M.İ., Sit. M.E. and Ercan, B. (2018) A Relationship between Flow Discharges, Sediment Discharge and Sub-Basin Areas in Ceyhan Catchment. 13th International Congress on Advances in Civil Engineering, Izmir, 12-14 September 2018.

[13] REMA (2010) Practical Tools on Land Management-GPS, Mapping and GIS. Report, Rwanda Environment Management Authority, Kigali.

[14] DeVere, B.L. (2010) Agri-Science: Fundamentals and Applications. Delmar Cengage Leaning, New York.

[15] Ezugwu, C. (2013) Sediment Deposition in Nigeria Reservoirs: Impacts and Control Measures. Innovative Systems Design and Engineering, 4, 54-62.

[16] Hannouche, A., Chebbo, G., Ruban, G., Tassin, B., Lemaire, B.J. and Joannis, C. (2011) Relationship between Turbidity and Total Suspended Solids Concentration within a Combined Sewer System. Water Science and Technology, 64, 2445-2452. https://doi.org/10.2166/wst.2011.779 
[17] Kusari, L. and Ahmedi, F. (2013) The Use of Turbidity and Total Suspended Solids Correlation for the Surface Water Quality Monitoring. International Journal of Current Engineering and Technology, 3, 1311-1314.

[18] WHO (2006) Guidelines for Drinking-Water Quality. 4th Edition, World Health Organization Press, Geneva.

[19] Bagalwa, J.J. (2015) Sediment and Nutrient Loading into Lake Kivu: A Case Study of Lwiro Micro-Catchment, Democratic Republic of Congo. MSc. Thesis, Makerere University, Kampala.

[20] Aldous, A., McCormick, P., Ferguson, C., Graham, S. and Craft, C. (2005) Hydrologic Regime Controls Soil Phosphorous Fluxes in Restoration and Undisturbed Wetlands. Restoration Ecology, 13, 341-347. https://doi.org/10.1111/j.1526-100X.2005.00043.x

[21] Cook, M.R., Moss, N.E., Rogers, A.L. and McKinney, M. (2014) Analysis of Sediment Loading Rates and Water Quality for the Bon Secour River Watershed Baldwin County, Alabama. Report, Geological Survey of Alabama, Tuscaloosa.

[22] Kwak, K. (2001) Prediction of Scour Depth versus Time for Bridge Piers in the Case of Multi-Flood and Multi-Layer Soil System. KSCE Journal of Civil Engineering, 5, 67-74. https://doi.org/10.1007/BF02830728

[23] Thapa, B.S., Dahlhaug, O.G. and Thapa, B. (2017) Sediment Erosion in Hydro Turbines and Its Effect on the Flow around Guide Vanes of Francis Turbine. Renewable and Sustainable Energy Reviews, 49, 1100-1113.

https://doi.org/10.1016/j.rser.2015.04.178

[24] Reisenbüchler, M., Bui, M.D., Skublics, D. and Rutschmann, P. (2020) Sediment Management at Run-Of River Reservoirs Using Numerical Modelling. Water, 12, 249. https://doi.org/10.3390/w12010249

[25] Serajuddin, M.D., Chowdhur, A.I., Haque, M.D. and Haque, E. (2019) Using Turbidity to Determine Total Suspended Solids in an Urban Stream: A Case Study. Proceedings of the 2 nd International Conference on Water and Environmental Engineering, Dhaka, 19-22 January 2019, 148-154.

[26] WASAC (2018) Raw and Treated Water Characteristics at Gihira Water Treatment Plant. Unpublished Data, Water and Sanitation Corporation, Kigali.

[27] IWRM (2017) Sebeya Catchment Plan 2017-2023. Report, Ministry of Natural Resources, Kigali.

[28] DFO (2000) Effects of Sediment on Fish and Their Habitat. Report, Department of Fisheries and Oceans, Vancouver.

[29] Tallar, R.Y. and Suen, J.-P. (2017) Measuring the Aesthetic Value of Multifunctional Lakes Using an Enhanced Visual Quality Method. Water, 9, 233.

https://doi.org/10.3390/w9040233

[30] Johnson, P. E. (2008) Erosion Control Handbook for Local Roads. US Department of Transportation, St. Paul.

[31] Morris, G. and Fan, J. (1998) Reservoir Sedimentation Handbook. McGraw-Hill Book Co, New York.

[32] Patil, S., Tushar, K.S. and Bhalerao, S.A. (2013) Mulching: A Soil and Water Conservation Practice. Research Journal of Agriculture and Forestry Sciences, 1, 26-29.

[33] Savadogo, P., Bayala, J. and Kalinganire, A. (2017) Restoration of Degraded Lands in Mali: A Review on Lessons Learnt and Opportunities for Scaling. Report, European Commission, Bamako.

[34] Gattinger, A., Jawtusch, J., Müller, A. and Mäder, P. (2011) No-Till Agriculture-A 
Climate Smart Solution. Report, Bishofliches Hilfswerk MISEREOR, Aachen.

[35] Pan, C. and Shangguan, Z. (2006) Runoff Hydraulic Characteristics and Sediment Generation in Sloped Grassplots under Simulated Rainfall Conditions. Journal of Hydrology, 331, 178-185. https://doi.org/10.1016/j.jhydrol.2006.05.011

[36] Fiener, P. and Auerswald, K. (2009) Effects of Hydrodynamically Rough Grassed Waterways on Dissolved Reactive Phosphorus Loads Coming from Agricultural Watersheds. Journal of Environmental Quality, 38, 548-559. https://doi.org/10.2134/jeq2007.0525

[37] Bugg, R.A., Donald, W., Zech, W. and Perez, M. (2017) Performance Evaluations of Three Silt Fence Practices Using a Full-Scale Testing Apparatus. Water, 9, 502. https://doi.org/10.3390/w9070502

[38] Fang, X., Wesley, C. and Christopher, P.L. (2015) Stormwater Field Evaluation and Its Challenges of a Sediment Basin with Skimmer and Baffles at a Highway Construction Site. Water, 7, 3407-3430. https://doi.org/10.3390/w7073407

[39] Pravat, K.S., Bhunia, G.S. and Ramkrishna, M. (2013) Assessing the Performance of Check Dams to Control Rill-Gully Erosion: Small Catchment Scale Study. International Journal of Current Research, 5, 899-906.

\section{Abbreviations and Acronyms}

DFO: Department of Fisheries and Oceans

GH: inlet of Gihira Water Treatment Plant

GSH: inlet of Gisenyi Hydropower Plant

HPPs: Hydropower Plants

IWRM: Integrated Water Resources Management

KY: inlet of Keya Hydropower Plant

MoE: Ministry of Environment

NISR: National Institute of Statistics of Rwanda

NPK: Nitrogen

Phosphorus and Potassium

NTU: Nephelometric Turbidity Unit

NYB: Nyamugari Bridge

REMA: Rwanda Environment Management Authority

SO: Sebeya Outlet

TSS: Total Suspended Solids

WASAC: Water and Sanitation Corporation

WHO: World Health Organization

WTP: Water Treatment Plant 